\title{
Bilateral lobar lung transplantation for cystic fibrosis - first in Poland
}

\author{
Marta Nieborak-Raczkowska ${ }^{1}$, Bartosz Kubisa ${ }^{2}$, Maria Piotrowska $^{2}$, Tomasz Grodzki ${ }^{2}$, Anna Kubisa ${ }^{1}$, \\ Jarosław Pieróg ${ }^{2}$, Małgorzata Wojtyś ${ }^{2}$, Michał Bielewicz², Michalina Czarnecka², Janusz Wójcik², \\ Norbert Wójcik ${ }^{2}$, Witold Sielicki ${ }^{3}$, Mirosław Brykczyński ${ }^{3}$ \\ ${ }^{1}$ Department of Internal Medicine and Hypertension, Regional Hospital, Szczecin-Zdunowo, Poland \\ 2Department of Thoracic Surgery and Transplantation, Pomeranian Medical University, Szczecin, Poland \\ ${ }^{3}$ Department of Cardiac Surgery, Pomeranian Medical University, Szczecin, Poland
}

Kardiochirurgia i Torakochirurgia Polska 2019; 16 (2): 97-99

Advances in the treatment of patients with cystic fibrosis (CF) are progressively prolonging their lives and its quality. The median life expectancy of CF patients is now 47.7 years, whereas approximately 30 years ago it was barely 27 years of age. Still respiratory failure is the most common primary cause of death in CF patients [1]. When all other therapies fail, lung transplantation remains the only viable option to prolong survival.

Various factors may influence the outcome of the lung transplant procedure. Size matching between donor and recipient is still considered to be one of the most crucial issues and in CF patients it is taken to another level as these individuals are often malnourished. As a result, this group of patients tends to have longer waiting times for transplantation [2]. Patients in need of urgent transplantation cannot wait for size-matched organs, and therefore various methods of cadaveric donor lung downsizing have been developed and successfully applied. Basically, there are three possible methods of lung tailoring - simple wedge resection, resection outside the anatomical borders and lobar transplantation. The latter is performed when there is a large size discrepancy between donor and recipient.

In 2017, a 23-year old female patient from Poland, of blood group $A$, who presented with cystic fibrosis, pulmonary hypertension and oxygen-dependent respiratory failure, was referred to our unit for further evaluation of possible lung transplantation. Since 2 years she has been experiencing the increasing frequency of exacerbations requiring antibiotic therapy and hospitalization. Preoperative chest X-ray and cpmputed tomography (CT) scanning demonstrated the presence of thick-walled bronchiectasis (Figs. $1 \mathrm{~A}, \mathrm{~B})$. The patient met the lung transplantation criteria according to the ISHLT guidelines [3]. An expedited workup was completed and the ethics committee approved the procedure. On June 19, 2017, the patient underwent the transplantation procedure. The transplanted organ was acquired from a 25-year old male patient, of blood group 0 , with the height of $183 \mathrm{~cm}$ and weight of $107 \mathrm{~kg}$, diagnosed with brain death due to intracranial injury resulting from a car accident. He had no relevant medical history. To overcome the magnitude of height disparity between the donor and the recipient, bilateral transplantation of single lower lobes was performed (Fig. 2).

The operation was performed on veno-arterial extracorporeal membrane oxygenation (VA-ECMO) with central cannulation. The surgical exposure was via bilateral thoracotomy and transverse sternotomy through the fifth intercostal space - the "clamshell" incision. The donor lungs were divided on the side table. The recipient's right and left lung were excised in a standard fashion. On the right side the donor's intermediate bronchus with stapled middle lobe bronchus was sutured to the recipient's right main bronchus. The recipient's pulmonary arteries were sutured to the donor's intermediate artery on the right side and to the lower lobe artery on the left. The donor's lower pulmonary veins were sutured to the recipient's pulmonary venous atrial cuff on both sides. Bronchial anastomoses were performed utilizing running absorbable PDS 4-0 monofilament suture and the vessels were sutured using running nonabsorbable Prolene 4-0 monofilament suture. Only 3000 IU of heparin were administered at the initiation of ECMO. The entire transplantation procedure lasted $5.5 \mathrm{~h}$.

During the surgical procedure there were no complications. The patient was transferred to the intensive care unit with a stay of 4 days. A single episode of acute allograft rejection was recognized and promptly treated, with good results. Treatment included discontinuation of cyclosporine with a switch to tacrolimus. The patient was hospitalized for 16 more days, with no additional clinical events. The patient is currently under the follow-up care carried out ev-

Address for correspondence: Marta Nieborak-Raczkowska, Department of Internal Medicine and Hypertension, Regional Hospital, 11 A. Sokołowskiego St, 70-891 Szczecin-Zdunowo, Poland, phone: +48 502488 244, e-mail: marsza.nieborak@gmail.com Received: 16.10.2018, accepted: 13.12.2018. 

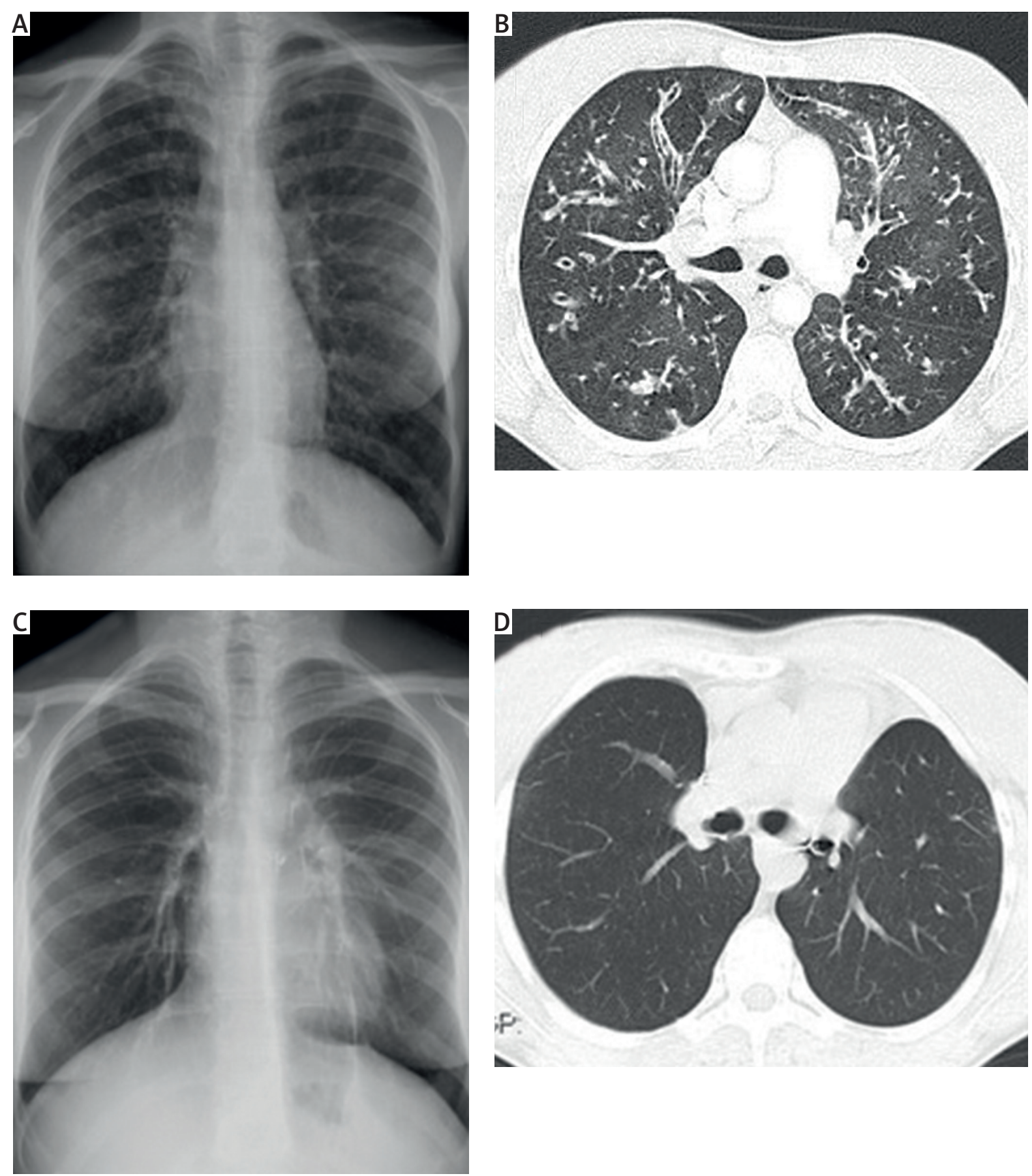

Fig. 1. A - Preoperative chest X-ray. B - Preoperative CT scanning showing the presence of thick-walled bronchiectasis. C - Chest X-ray performed 6 months after the transplantation. D - CT scanning performed one year after the transplantation showing no significant pulmonary findings

ery 6 months. No other complications have been recorded. Chest X-ray performed 6 months after the transplantation and CT scanning performed 1 year after the surgery showed no significant pulmonary findings (Figs. 1 C, D).

Cadaveric transplantation has been the basic approach since the beginning of lung transplantation, but it is still limited by the scarcity of the donor pool. As the number of patients on the transplant waiting list increases yearly, compromises must be made to provide organs for those critically ill. Sometimes additional compromises are made in terms of donor-recipient size matching, but there have been several reports that a mismatched lung graft may cause potential problems [4-6]. The oversized graft may lead to poorer gas exchange, elevated pulmonary vascular resistance, impaired diaphragm movement, atelectasis and an increased risk for secondary infection. On the other hand, an undersized graft may over-inflate and lead to persistent pleural effusion, increased breathing effort 
and, in extreme cases, hemodynamic instability. The use of cadaveric lobar transplantation is still not considered to be a standard procedure, in spite of the fact that it allows larger grafts to be used in urgent pediatric and small adult patients with no time to wait for an ideal size-matched donor. In our experience this procedure is safe, does not add significant morbidity and its achieved outcome rates are equivalent to those for lung transplantation with sizematched grafts. Similar conclusions have been reached by other studies $[5,6]$. To the best of our knowledge, this is the first report regarding this type of lung transplantation procedure performed in Poland. Carefully selected patients with size-unmatched donors demonstrate results that are comparable to those of lung transplantation with sizematched grafts. We hope that this report will encourage other units to consider cadaveric lobar transplantation for their urgently listed patients with a smaller chest cavity.

\section{Disclosure}

The authors report no conflict of interest.

\section{References}

1. Cystic Fibrosis Foundation. Cystic Fibrosis Foundation Patient Registry. 2016 Annual Data Report. Bethesda, Maryland, 2017.

2. Marasco SF, Than S, Keating D, Westall G, Whitford H, Snell G, Gooi J, Williams T, Pick A, Zimmet A, Lee GA. Cadaveric lobar lung transplantation: technical aspects. Ann Thorac Surg 2012; 93: 1836-1842.

3. Weill D, Benden C, Corris PA, Dark JH, Davis RD, Keshavjee S, Lederer DJ, Mulligan MJ, Patterson GA, Singer LG, Snell GI, Verleden GM, Zamora MR, Glanville AR. A consensus document for the selection of lung transplant candidates: 2014 - an update from the Pulmonary Transplantation Council of the International Society for Heart and Lung Transplantation. J Heart Lung Transplant 2015; 34: 1-15.

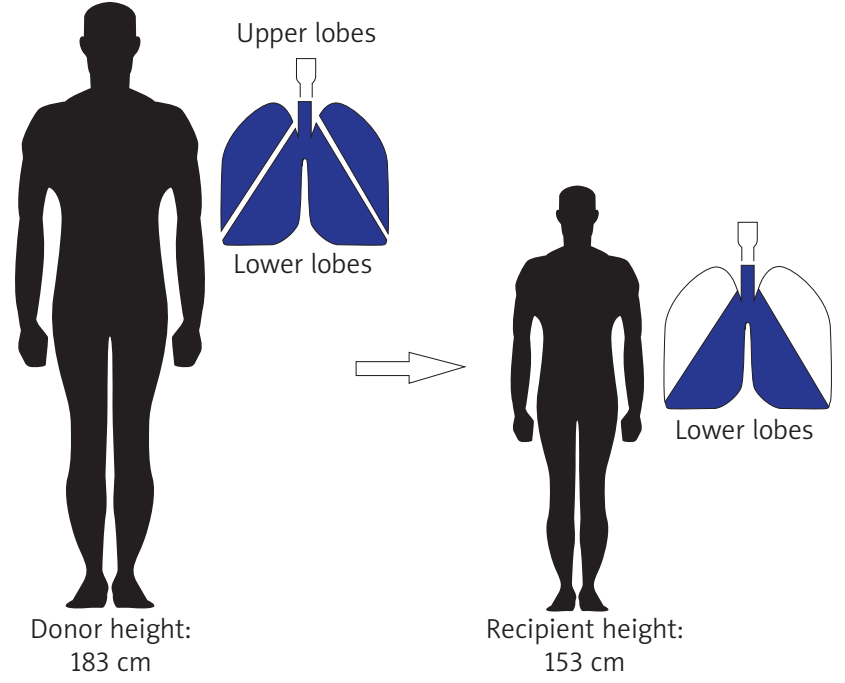

Fig. 2. Bilateral lobar transplant was performed to overcome the magnitude of height disparity between the donor and the recipient

4. Orens JB, Boehler A, de Perrot M, Estenne M, Glanville AR, Keshavjee S, Kotloff R, Morton J, Studer SM, Van Raemdonck D, Waddel T, Snell Gl; Pulmonary Council, International Society for Heart and Lung Transplantation. A review of lung transplant donor acceptability criteria. J Heart Lung Transplant 2003; 22: 1183-1200.

5. Santos F, Lama R, Alvarez A, Algar FJ, Quero F, Cerezo F, Salvatierra A, Baamonde C. Pulmonary tailoring and lobar transplantation to overcome size disparities in lung transplantation. Transplant Proc 2005; 37: 1526-1529.

6. Aigner C, Mazhar S, Jaksch P, Seebacher G, Taghavi S, Marta G, Wisser W, Klepetko W. Lobar transplantation, split lung transplantation and peripheral segmental resection - reliable procedures for downsizing donor lungs. Eur J Cardiothorac Surg 2004; 25: 179-183. 